\title{
Statins Reduce Dengue Virus Production via Decreased Virion Assembly
}

\author{
Marlén Martínez-Gutierrez ${ }^{\mathrm{a}} \quad$ Jaime E. Castellanos ${ }^{\mathrm{c}}$ \\ Juan C. Gallego-Gómez ${ }^{\text {a, b }}$

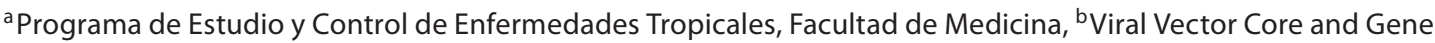 \\ Therapy, Neuroscience Group, Facultad de Medicina, Universidad de Antioquia, Medellín, y `Grupo de Virología, \\ Universidad El Bosque, Bogotá, Colombia
}

\author{
Key Words \\ Dengue virus · Statins · Assembly · Cholesterol • \\ Protein prenylation
}

\begin{abstract}
Background: Most of the effects of statins can be explained by pleiotropic effects independent of their lowering of serum cholesterol; in some cases, these effects have been shown to be a result of the role of statins in the prenylation of cellular proteins, some of which are involved in the life cycle of animal viruses. This study evaluated the potential antiviral activity of lovastatin (LOV) against dengue virus (DENV) infection of epithelial and endothelial cells (VERO cells, epithelial cells derived from African green monkey kidney, and HMEC-1 cells, human dermal microvascular endothelial cells). Methods: To evaluate its potential antiviral effects, LOV was used before, during and after inoculation of cell cultures with DENV. Results: Before and after viral inoculation, LOV caused a reduction in virus yield (80\% for HMECs and $25 \%$ for VERO cells). However, with LOV treatment after inoculation induced a marked increase (2- to 9-fold) in viralpositive RNA while the amount of viral protein increased only by $13-23 \%$. A moderate reduction (1 log unit) in viral titer occurred concurrent with the increase in DENV genomic RNA and protein within the cells. Conclusions: According
\end{abstract}

to our results, LOV appears to have a greater effect on viral assembly than on replication, resulting in the cellular presence of viral genomic RNA and proteins that fail to take the normal assembly pathway.

Copyright $\odot 2011$ S. Karger AG, Basel

\section{Introduction}

Dengue virus (DENV), which belongs to the family Flaviviridae and genus Flavivirus, has become one of the most important vector-borne viruses in the world [1]. The 4 known DENV serotypes (DENV 1-4) have a transmission cycle that requires invertebrate vectors (mosquitoes Aedes aegypti, albopictus and polynesiensis) and primates (predominantly humans) [2]. Infection by DENV can manifest as various illnesses, ranging from nonsevere dengue fever to severe dengue hemorrhagic fever and dengue shock syndrome [3].

Annually, between 50 and 100 million cases of dengue occur worldwide. In 2008, there were close to 1 million cases of dengue fever and 25,000 cases of dengue hemorrhagic fever reported in the Americas alone [4]. As a result of demographic changes, rapid urbanization and globalization, dengue is now considered an emerging infectious disease [5], and a recent increase in genotype

\section{KARGER \\ Fax +41 613061234 \\ E-Mail karger@karger.ch}

www.karger.com (c) 2011 S. Karger AG, Basel

0300-5526/11/0544-0202\$38.00/0

Accessible online at: www.karger.com/int
Juan C. Gallego-Gómez

Calle 62 \#52-59, lab. 412

Medellín (Colombia)

Tel. +57 42196444 02, Fax +57 42196444

E-Mail juanc.gallegomez@gmail.com 
diversification has been shown [6]. Currently, there are no vaccines or specific treatments for dengue. Despite the increase in the number of evaluated drugs with antiviral activity over the past few years [7], none have been used in humans until now.

The single-stranded positive-sense RNA DENV genome encodes 3 structural and 7 nonstructural proteins [8]. The replication cycle begins with the binding of envelope (E) protein to receptors on the cell membrane, including heparan sulfate [9], DC-SIGN [10], Hsp70, Hsp90 [11] and GRP78/P proteins [12]. After binding, clathrinmediated endocytosis occurs [13], followed by endosome formation and fusion of the viral envelope with the endosome [14]. This facilitates the release of viral RNA into the cytoplasm, allowing translation of the viral polyprotein by ribosomes associated with the endoplasmic reticulum (ER). Following cleavage of the polyprotein by cellular and viral (NS2B/NS3) proteases [15], the viral replication complex (RNA, NS5, nonstructural proteins and cellular factors) forms in association with intracellular membranes. It has been proposed that viral translation and replication occurs in association with amphisomes (endosomes fused to autophagosomes) inside the cells [16]. The assembly of viral proteins with new viral RNA occurs in the lumen of the ER, followed by the release of new virions through budding from the ER into the Golgi apparatus. Through this process, the virions acquire a lipid envelope in which the immature forms of $\mathrm{M}$ (prM) and $\mathrm{E}$ proteins are inserted. Viral maturation occurs in the Golgi and trans-Golgi network, where the cleavage of prM by cellular furin takes place [17]. Despite the inefficiency of this process, it is critical to the infectious capacity of the new virions [18]. Finally, mature infectious virus particles are released from the cells by exocytosis.

Statins are inhibitors of 3-hydroxy-3-methylglutaryl coenzyme A reductase, an enzyme that catalyzes the conversion of hydroxymethylglutarate to mevalonic acid in the mevalonate (MEV) pathway [19]. Since the discovery of statins, several mechanisms of action have been described, the most important being the inhibition of cholesterol synthesis [20]. However, blockage of the cholesterol synthetic pathway affects not only cholesterol synthesis but also other processes, such as the synthesis of isoprenoids, lipid intermediates necessary for protein prenylation; dolichol phosphate, which is involved in protein glycosylation; and ubiquinone, which is involved in respiratory chain activity [21]. Statins also affect cellular processes that are independent of the MEV pathway, such as the binding of leukocyte function antigen 1 to intercellular adhesion molecule 1 [22]. All mechanisms not re-

Antiviral Effects of Statins on Dengue Virus Infection lated to the inhibition of cholesterol synthesis are termed 'pleiotropic effects'. The process of protein prenylation involves the covalent binding of isoprenoids (farnesyl, FPP or geranylgeranyl pyrophosphate, GGPP) to proteins. Prenylated proteins include members of the small GTPase Ras superfamily, which encompasses the Ras, Rho, Sarl/Arf, Ran and Rab subfamilies [23], each of which is involved in a unique set of cellular processes [24].

Given that the replication cycle of many viruses involves cholesterol, isoprenylated proteins, and/or intercellular adhesion molecules, statins would be expected to have inhibitory effects on viral replication. Studies using cultured cells have demonstrated inhibitory effects of statins on the replication of RNA and DNA viruses, including respiratory syncytial virus [25], hepatitis $C$ virus [26], human immunodeficiency virus [27], rotavirus [28], and cytomegalovirus [29]. In some cases, including hepatitis $\mathrm{C}$ and human immunodeficiency viral infection, their activity has been assessed in infected patients, demonstrating a decrease in the severity of infection $[27,30]$.

Recently, it was discovered that heat shock proteins 90 and 70 (HSP90 and HSP70) are components of the cellular receptor implicated in DENV entry [11]. In that study, it was demonstrated that both proteins are associated with lipid rafts; when cell cultures were treated with methyl- $\beta$-cyclodextrin (a lipid raft disruptor), DENV infection was inhibited. This finding is consistent with the idea that lipid rafts could recruit HSPs to specific areas of the plasma membrane, where DENV can trigger cellular events related to pathogenesis. Further support comes from the observation that some viral proteins that participate in viral replication are associated with these rafts [31]. Moreover, it was recently demonstrated that cholesterol is important in the replication of other members of the Flaviviridae family, including West Nile virus and Japanese encephalitis virus [32, 33].

Given these antecedents, it would be logical to think that blocking cholesterol metabolism with lipid-lowering drugs, which has been widely established in medical therapy, could affect DENV infection. Recently, pharmacological and genetic studies by Rothwell et al. [34] found that agents that interfere with the cholesterol biosynthetic pathway can regulate the replication of DENV. Using RNA interference methodology, they demonstrated that the knock-down of MEV diphosphate decarboxylase, a molecule implicated in cholesterol biosynthesis that acts downstream of the molecular target of statins, produced a significant reduction in DENV infections and a decreased replication of RLuc replicons. Additionally, the authors showed that blocking and restoring alternative 
pathways of cholesterol synthesis (prenylation) failed to explain the reduced DENV infection rate. For these reasons they postulated that the sterol branch of cholesterol metabolism (squalene) could be necessary for DENV replication [34].

The work presented here, however, postulates an alternative mechanism by which viral infection is blocked. Our hypothesis is that, rather than inhibiting the RNA synthesis of DENV, statins counteract the assembly process of the virus in cell cultures. The aim of this study was to determine the effect of lovastatin (LOV) on DENV-2 infection in vitro and to explore the possible cellular mechanism(s) involved; for this purpose, two kinds of cell lines (VERO cells, epithelial cells derived from African green monkey kidney, and HMEC-1 cells, human dermal microvascular endothelial cells) were employed. The data presented here suggest that statins delay the assembly process of DENV in cell cultures. After statin treatment, we observed a larger amount of viral protein and genomic RNA in the cultures, with fewer assembled viruses as measured by the titer of infectious virions. Further ultrastructural studies by electron microscopy are essential to confirm the findings presented here and to identify appropriate in vivo models that clarify the potential role of statins as therapeutic and/or preventive drugs for viral infections.

\section{Materials and Methods}

\section{Reagents}

Dulbecco's modified Eagle's medium (DMEM), MCDB-131 medium, fetal bovine serum (FBS), penicillin/streptomycin and amphotericin were purchased from Invitrogen Life Technologies (Carlsbad, Calif., USA). LOV and 3-(4,5-dimethylthiazol-2-yl)2,5-diphenyl tetrazolium bromide (MTT) were obtained from Sigma-Aldrich Chemical Co. (St. Louis, Mo., USA). LOV was resuspended in ethanol $(20 \mathrm{mM})$ and diluted in DMEM to a final concentration of $2 \mathrm{mM}$ before being stored at $-20^{\circ}$. Human epidermal growth factor and hydrocortisone were obtained from MP Biomedicals (Irvine, Calif., USA). The primary antibody against DENV (Anti-Dengue Virus Type II, clone 3H5-1) was purchased from Chemicon International, Inc. (Temecula, Calif., USA). Secondary biotinylated antibody (Biotinylated Horse Anti-Mouse/ Rabbit IgG Antibody) and horseradish peroxidase-conjugated streptavidin were obtained from Vector Labs (Burlingame, Calif., USA). Phalloidin conjugated with rhodamine and Alexa Fluor ${ }^{\circledR}$ 488 anti-mouse were purchased from Sigma-Aldrich Chemical Co. and Molecular Probes Invitrogen Life Technologies, respectively.

Virus and Cells

DENV type 2 (New Guinea strain) obtained from Maria Elena Peñaranda and Eva Harris (Sustainable Sciences Institute and the University of California at Berkeley) was amplified in C6/36HT (of A. albopictus cells), which were donated by Guadalupe Guzman (Virology Department, Pedro Kouri Institute, La Havana, Cuba). Virus stocks were titrated in VERO cells obtained from the American Type Culture Collection. The HMEC-1 cell line was kindly provided by Francisco Candal of the Centers for Disease Control and Prevention (Atlanta, Ga., USA). VERO and C6/36 HT cells were maintained in DMEM supplemented with $10 \%$ FBS. VERO cells were incubated at $37^{\circ}$ in a $5 \% \mathrm{CO}_{2}$ atmosphere and $\mathrm{C} 6 / 36 \mathrm{HT}$ at $34^{\circ}$ in a $5 \% \mathrm{CO}_{2}$ atmosphere. HMEC-1 cells were grown at $37^{\circ}$ in $5 \% \mathrm{CO}_{2}$ in $\mathrm{MCDB} 131$ medium supplemented with FBS (10\%), human epidermal growth factor $(10 \mathrm{ng} / \mathrm{ml})$ and hydrocortisone $(1 \mu \mathrm{g} / \mathrm{ml})$. DMEM and MCDB-131 were supplemented with penicillin/streptomycin $(100 \mathrm{U} / \mathrm{ml}$ and $100 \mu \mathrm{g} / \mathrm{ml}$, respectively) and amphotericin $(0.25 \mu \mathrm{g} / \mathrm{ml})$.

\section{Cytotoxicity Assay}

The MTT cell proliferation assay was conducted to estimate the cytotoxicity of LOV; $2.5 \times 10^{4}$ VERO cells were seeded into 96-well culture plates. After $24 \mathrm{~h}$ incubation, the medium was removed and replaced with medium containing serial dilutions of LOV: $1.25,2.5,5,10$ and $20 \mu \mathrm{M}$. At different times $(3,6,12,24,36$, 48 and $72 \mathrm{~h})$, LOV was removed, and $50 \mu \mathrm{l}$ of MTT $(0.5 \mathrm{mg} / \mathrm{ml}$, prepared in PBS) was added to each well. After $3 \mathrm{~h}$ incubation at $37^{\circ}$ in $5 \% \mathrm{CO}_{2}, 100 \mu \mathrm{l}$ of dimethyl sulfoxide was added to each well to solubilize the formazan crystals, and the plates were subsequently incubated for $15 \mathrm{~min}$. Absorbance at $450 \mathrm{~nm}$ was read on a Benchmark microplate reader (Bio-Rad Laboratories, Hercules, Calif., USA). All determinations were performed twice, each in duplicate $(n=4)$.

\section{DENV Infection, LOV, Agonist and Antagonist Treatment}

Three different experimental protocols were used to evaluate the effect of LOV treatment on antiviral activity according to previously reported protocols [35]. (1) Before viral inoculation: the cells were treated for $24 \mathrm{~h}$ with LOV, the medium was then removed, and the cells were washed and incubated with DENV 2 at a MOI of 1 for $1 \mathrm{~h}$ at $37^{\circ}$. After removing the viral inoculum, the cells were washed and incubated for $24 \mathrm{~h}$ in medium without LOV. (2) During viral inoculation : the viral inoculum (MOI 1) was prepared in medium with LOV and added to the culture for $1 \mathrm{~h}$. Subsequently, the inoculum was discarded, and the cells were incubated for $24 \mathrm{~h}$ in medium without LOV. (3) After viral inoculation: cells were inoculated with DENV 2 (MOI 1 ) for $1 \mathrm{~h}$, and LOV was added to the culture immediately after discarding the viral inocula. In all approaches, supernatants were collected $24 \mathrm{~h}$ after viral inoculation, and monolayers were either fixed or collected to evaluate the antiviral activity by three different methods: cell enzyme-linked immunosorbent assay (cell-ELISA) and reverse transcription and quantitative real-time PCR (RT-qPCR), which were done on monolayers to determine the effect of LOV on the production of viral protein and viral RNA, respectively, and a plaque formation assay that was performed using supernatants to evaluate the effect of treatment on virus yield.

In an attempt to identify the mechanism(s) by which LOV inhibits viral infection, we treated cell cultures with LOV alone or with LOV in combination with $200 \mu \mathrm{M} \mathrm{MEV}, 5 \mu \mathrm{g} / \mathrm{ml}$ cholesterol, $5 \mu \mathrm{M}$ GGPP or $5 \mu \mathrm{M}$ FPP. In some cases, the cultures were treated with $10 \mu \mathrm{M}$ geranylgeranyl transferase-I inhibitor (GGTI-286) or $10 \mu \mathrm{M}$ farnesyl transferase inhibitor (FTI-277) alone. These treatments were performed before or after viral inoculation. 


\section{Cell-ELISA}

Viral protein was quantified by a spectrophotometric cell-ELISA, a modification of the fluorometric cell-ELISA previously described [36]. Briefly, VERO and HMEC-1 cells submitted to different experimental strategies were fixed with $4 \%$ paraformaldehyde for $30 \mathrm{~min}$ and permeabilized with $0.1 \%$ Triton X-100 for $30 \mathrm{~min}$. Afterwards, endogenous peroxidase was quenched with $0.3 \%$ $\mathrm{H}_{2} \mathrm{O}_{2}$ in $10 \%$ methanol in PBS, and nonspecific sites were saturated with blocking buffer (10\% FBS in PBS). Primary (mouse anti-DENV) and secondary biotinylated anti-mouse IgG diluted in blocking buffer were incubated for $1 \mathrm{~h}$; then, horseradish peroxidase-conjugated streptavidin was added for $30 \mathrm{~min}$. Finally, the reaction was revealed using the Sigma Fast ${ }^{\circledR}$ OPD (St. Louis, Mo., USA) substrate system, and the absorbance at $405 \mathrm{~nm}$ was read on a Benchmark microplate reader (Bio-Rad Laboratories). For normalization of the data, the protein concentration in each well was determined using a Bradford assay. Data are presented as the ratio of absorbance to total protein in each well. Two independent experiments were performed, with 3 replicates for each assay $(n=6)$.

\section{Reverse Transcription and Quantitative Real-Time PCR}

Total RNA was extracted from monolayers using the Qiagen RNeasy Mini Kit (Qiagen Inc., Valencia, Calif., USA) according to the manufacturer's instructions. Retrotranscription was done from $1 \mu \mathrm{g}$ total RNA using random primers and M-MLV reverse transcriptase. Finally, cDNAs were amplified using primers previously reported: DV2C-L: 5' - CAA TAT GCT GAA ACG CGA GA-3' and DV2C-R: 5'-TGC TGT TGG TGG GAT TGT TA-3 [37]. Using aDNA Engine Opticon 2 real-time detection system (MJ Research), qPCR was conducted over 40 cycles in $50-\mu l$ reactions containing cDNA, SYBR Green I dye (DyNAmo master mix, Finnzymes) and the corresponding primers. A 10 -fold dilution of a plasmid containing a sequence encoding a fragment (151 bp) of capsid protein was used as a template in standard-curve analysis. Analyses were performed from at least 2 independent experiments with 2 replicates each $(n=4)$.

\section{Viral Titration by Plaque Assay}

Infectious viruses were measured by plaque assay in VERO cells. At $24 \mathrm{~h}$ prior to use, cells were seeded into a 24 -well culture plate at a concentration of $5 \times 10^{4}$ cells per well. Serial 10 -fold dilutions $\left(10^{-1}-10^{-5}\right)$ of mature virus collected from supernatants under different experimental conditions were prepared and added to the cells. After $1 \mathrm{~h}$, the medium was removed and semisolid medium (1.5\% of carboxymethylcellulose prepared in DMEM with $2 \%$ FBS) was added to each well. Following incubation for 7 days, the number of plaques per well was counted, and the PFUs in the original inoculum (PFU/ml) were determined. Results were expressed as the average of at least 2 independent assays with 2 replicates for each assay $(n=4)$.

\section{Fluorescence Microscopy}

To evaluate the effects of LOV on the number of infected cells and on the subcellular distribution of viral proteins, VERO and HMEC-1 cells were grown on glass coverslips at a density of 2.5 $\times 10^{4}$ cells per coverslip and subjected to different experimental protocols (before, during and after viral inoculation). In all cases, the cells were treated with LOV at $20 \mu \mathrm{M}$ and infected with DENV 2 at a MOI of 10. At $48 \mathrm{~h}$ after inoculation, cell monolayers were washed with cytoskeletal buffer (CB) as previously described [38] to preserve delicate elements of the cytoskeleton and fixed with $3.8 \%$ paraformadehyde in $\mathrm{CB}$ at $37^{\circ}$ for $30 \mathrm{~min}$. The monolayers were permeabilized with $\mathrm{CB}$ containing $0.5 \%$ Triton $\mathrm{X}-100$, blocked with a solution of CB containing 5\% FBS and incubated with primary anti-DENV antibody (1:500) followed by incubation with anti-mouse secondary antibody conjugated with Alexa 488, rhodamine-conjugated phalloidin and Hoechst 33258 dye. Finally, the cells were washed with $\mathrm{CB}$ and the coverslips were mounted. Images were obtained using an inverted microscope (IX-81 Olympus ${ }^{\circledR}$ ). The images were captured by software (Media Cybernetics, Image Pro Plus ${ }^{\circledR}$ ) and improved in contrast, intensity and brightness using only linear modifications in Adobe Photoshop 9.0, according to Rossner $[39,40]$.

\section{One-Step Virus Growth Curve}

VERO and HMEC-1 cells were seeded on 24-well culture plates at a concentration of $5 \times 10^{4}$ cells per well. After $24 \mathrm{~h}$, the cells were incubated at $4^{\circ}$ for $1 \mathrm{~h}$ with DENV 2 (MOI of 10), washed 3 times with cold PBS, given fresh DMEM and incubated at $37^{\circ}$ for $2,4,6,8,10,12,16,20$ and $24 \mathrm{~h}$. Supernatants were collected and stored at $-70^{\circ}$ until titration. To quantify the cell-associated virus, the monolayers were washed, resuspended in DMEM and harvested by scraping and centrifugation. To elucidate where the effect of LOV occurs in the viral replication cycle, VERO and HMEC-1 cells were inoculated at an MOI of 10 , incubated for $1 \mathrm{~h}$, and subsequently treated (once) with $20 \mu \mathrm{M} \mathrm{LOV}$ at different times: $0,2,4,6,8,10,12,16$ and $20 \mathrm{~h}$. Infectious viral particles in supernatants were measured by plaque assay titration.

\section{Statistics}

To compare the amounts of viral protein in cultures treated with different concentrations of LOV with the amounts in untreated cultures, cell-ELISA data were evaluated using one-way analysis of variance followed by least significant-difference tests (ANOVA-LSD). To compare the number of viral infectious particles or the number of viral RNA copies between cultures treated and not treated with LOV, a Student $t$ test was used. In all cases, $p<0.05$ was considered to be statistically significant.

\section{Results}

\section{LOV Affects the Amount of Viral Protein in VERO and HMEC-1 Cells in a Dose-Dependent Manner}

We found that LOV reduced cellular viability in both cell lines ( $\mathrm{p}<0.05$, ANOVA-LSD) when it was in contact with the cells for longer than $24 \mathrm{~h}$ (fig. 1). For this reason, all subsequent antiviral assays were done using a maximum of $20 \mu \mathrm{M}$ LOV for $24 \mathrm{~h}$. To evaluate whether LOV changes viral protein levels, a cell-ELISA assay was performed. We found that, when added to cultures $24 \mathrm{~h}$ before viral inoculation, LOV reduced the amount of intracellular viral protein. The signal was significantly lower than in the control (13 and 18\% for VERO and 23 and $25 \%$ for HMEC-1 cells, respectively) at concentrations of 10 and $20 \mu \mathrm{M} \mathrm{LOV} \mathrm{(fig.} \mathrm{2a).} \mathrm{When} \mathrm{LOV} \mathrm{was} \mathrm{added} \mathrm{imme-}$ 

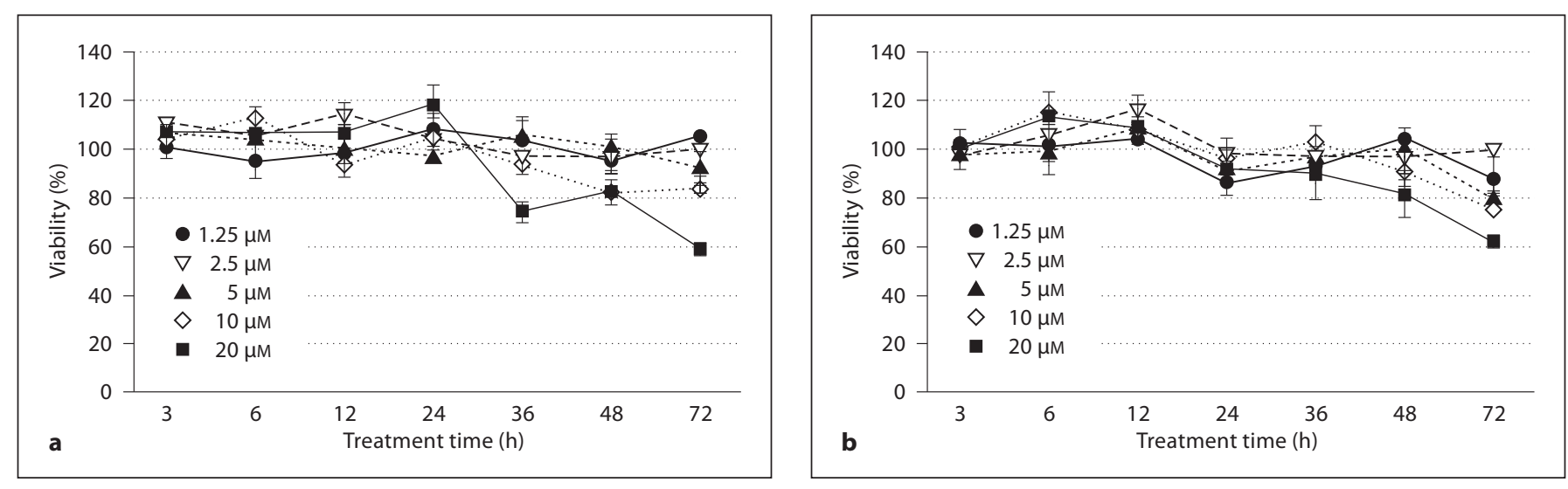

Fig. 1. Viability of cultures treated with LOV. VERO (a) and HMEC-1 (b) cells were treated with different concentrations of $\operatorname{LOV}(1.25,2.5,5,10$ and $20 \mu \mathrm{M})$. At different times $(3,6,12,24,36,48$ and $72 \mathrm{~h})$, the cultures were processed using the MTT technique. The values represent the means \pm SEM of 2 independent experiments, each with 2 replicates for each condition $(n=4)$.

diately after virus withdrawal, the amount of viral protein was higher compared with the control without LOV (12 and 13\% for VERO cells and 22 and 23\% for HMEC-1 cells, respectively) (fig. 2c). The magnitude of inhibition was dose dependent, with increasing concentrations (10 and $20 \mu \mathrm{M}$ ) of LOV showing increasing inhibitory effects $(\mathrm{p}<0.05$, ANOVA-LSD). When cultures received LOV and viral inocula simultaneously, we did not find significant differences in the amounts of viral protein (fig. 2b).

These results correlate with the number of infected cells detected by an indirect immunofluorescence assay. In cultures treated with LOV prior to viral inoculation, we observed a reduction (approx. 50\%) in the number of infected cells compared with LOV-untreated controls, and in some cases, a slight intracellular accumulation of viral protein (fig. $2 \mathrm{e}, 7 \mathrm{~g}$ ). In cultures treated with LOV during viral inoculation, no differences either in the number of infected cells or in the levels of intracellular proteins were observed compared with control cultures (fig. 2g, 7j). Finally, in cultures treated after viral inoculation, we did not observe changes in the number of infected cells compared with LOV-untreated controls; however, we found a strong intracellular accumulation of viral protein as measured by cell-ELISA and fluorescence microscopy (fig. $2 \mathrm{i}, 7 \mathrm{~m}$ ). The values shown represent the means of 2 independent experiments, with 2 replicates for each condition \pm SEM $(n=4)$.

\section{LOV Affects Viral mRNA Levels in Infected Cells}

We performed RT-qPCR to quantify levels of viral RNA in cell cultures. In concordance with the observed increase in the amount of viral protein, we found increased levels of viral RNA in VERO (fig. 3a) and HMEC1 (fig. 3b) cells treated with $20 \mu \mathrm{M}$ LOV after viral inoculation. The percentage increase (226 and 914\% in VERO and HMEC-1 cells, respectively) was statistically significant compared with LOV-untreated controls $(\mathrm{p}<0.05$, Student's t test). We did not observe changes in the levels of viral RNA in LOV-pretreated cells, but we found increased levels of viral RNA (168\%) in HMEC-1 cells treated with LOV during infection.

\section{LOV Inhibits Virus Yield in Treated Cultures}

A plaque assay was used to quantify mature infectious viruses released into the supernatants of VERO (fig. 4a) and HMEC-1 (fig. 4b) cell cultures. Despite the increases in viral protein and mRNA, we found that LOV significantly reduced the amount of infectious viral particles released from cells when added before or after viral inoculation ( $p<0.05$, Student's $t$ test). The same effect of LOV on viral production in VERO cells was observed when we tested two additional strains of DENV 2: a reference strain (16681) and a Colombian clinical isolate (No. 415-1, donated by Dr. Rey from the Colombian National Health Institute) (data not shown). The inhibition was more evident in HMEC-1 cells treated with LOV before (86\%) and after (84\%) viral inoculation than in VERO cells treated with LOV before (25\%) and after (26\%) viral inoculation. When LOV was added during viral inoculation, we found a significant inhibition (27\%) of infectious viral particles released only from HMEC-1 cells. Moreover, the selectivity index of LOV was obtained (table 1). 

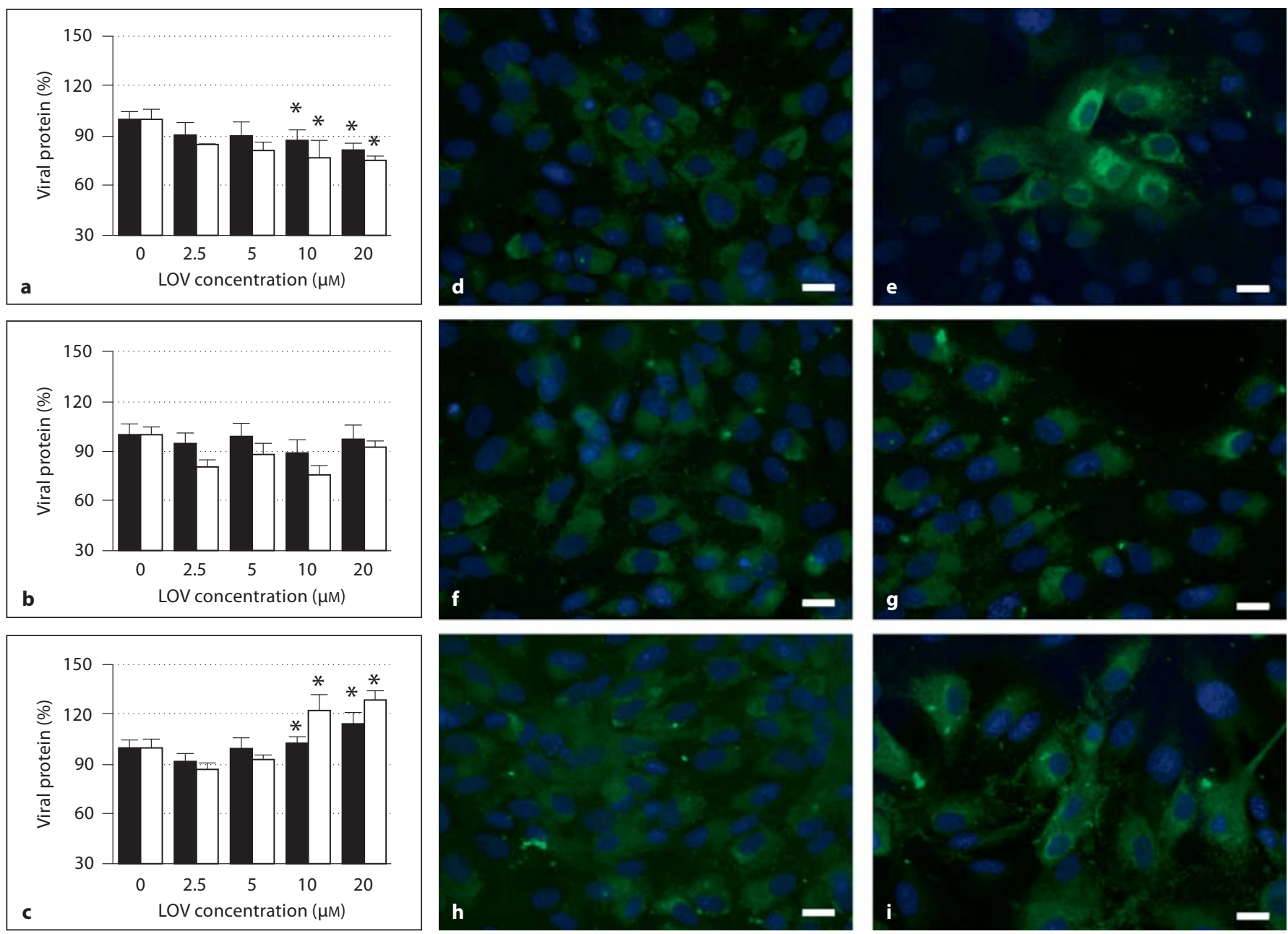

Fig. 2. Intracellular detection of DENV protein in cultures treated with LOV. a-c Cell-ELISA assay to evaluate intracellular levels of viral proteins in VERO cells ( $\square$ ) and HMEC-1 ( $\square$ ). The cultures were treated with different concentrations of LOV before (a), during (b), or following (c) viral inoculation and the supernatants were collected $24 \mathrm{~h}$ after viral inoculation. The values represent the means \pm SEM of 2 independent experiments with 3 replicates

for each condition $(n=6)$. The asterisk indicates a significant difference compared with LOV-untreated controls (ANOVA-LSD; $\mathrm{p}<0.05)$. Immunofluorescence analysis of DENV 2 proteins in untreated VERO cells $(\mathbf{d}, \mathbf{f}, \mathbf{h})$ or in VERO cells treated with LOV before (e), during (g) or after (i) viral infection. Representative images are shown $(n=4)$. Scale bar: $10 \mu \mathrm{m}$.

LOV Affects the Final Steps of Growth Curve of DENV in Cells

A one-step virus growth curve of DENV-2 in VERO and HMEC-1 cells was established to identify the stages of the replication cycle, and it was subsequently used to determine which stages of the cycle were inhibited by LOV treatment. In VERO cells, the eclipse phase corresponding to viral uncoating, protein synthesis, and genome replication occurred within the first $4 \mathrm{~h}$, with assembly and maturation beginning at $4 \mathrm{~h}$ and continuing until $12 \mathrm{~h}$ after infection. DENV release from VERO cells
Table 1. LOV selectivity index (SI) in VERO and HMEC-1 cells infected with DENV-2

\begin{tabular}{llll}
\hline & $\mathrm{CC}_{50}$ & $\mathrm{IC}_{50}$ & $\mathrm{SI}$ \\
\hline VERO cells & 57.2 & 38.4 & 1.4 \\
HMEC-1 cells & 53.6 & 11.9 & 4.5 \\
\hline
\end{tabular}

$\mathrm{CC}_{50}=$ Concentration that inhibited the cellular viability to $50 \%$ measured by MTT technique; $\mathrm{IC}_{50}=$ concentration that inhibited the virus growth to $50 \%$ measured by plaque assay; $\mathrm{SI}=\mathrm{CC}_{50} / \mathrm{IC}_{50}$. 


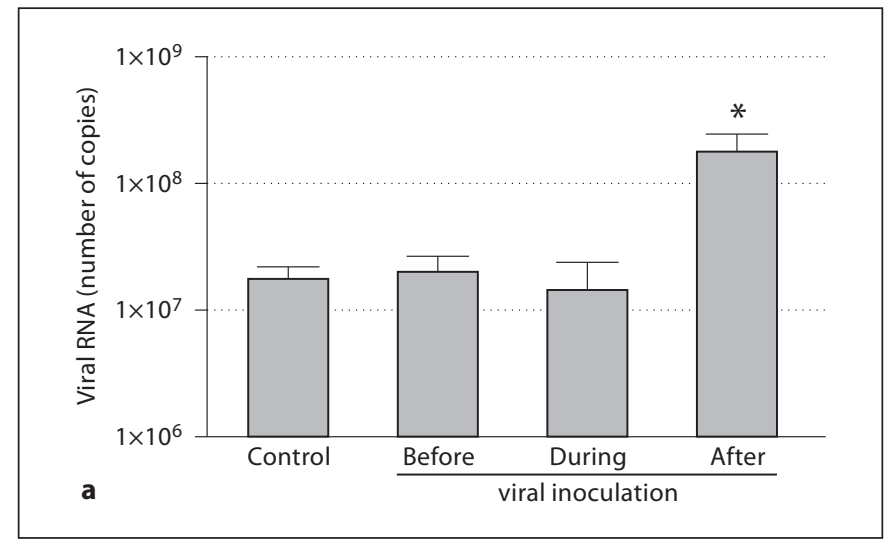

Fig. 3. Viral RNA quantification in VERO (a) and HMEC-1 (b) cells treated with LOV. Cell cultures were treated with $20 \mu \mathrm{M}$ LOV before, during, or following viral inoculation (MOI 1). Twenty-four hours after viral inoculation, total RNA was extracted from monolayers and RT-qPCR was performed. The values

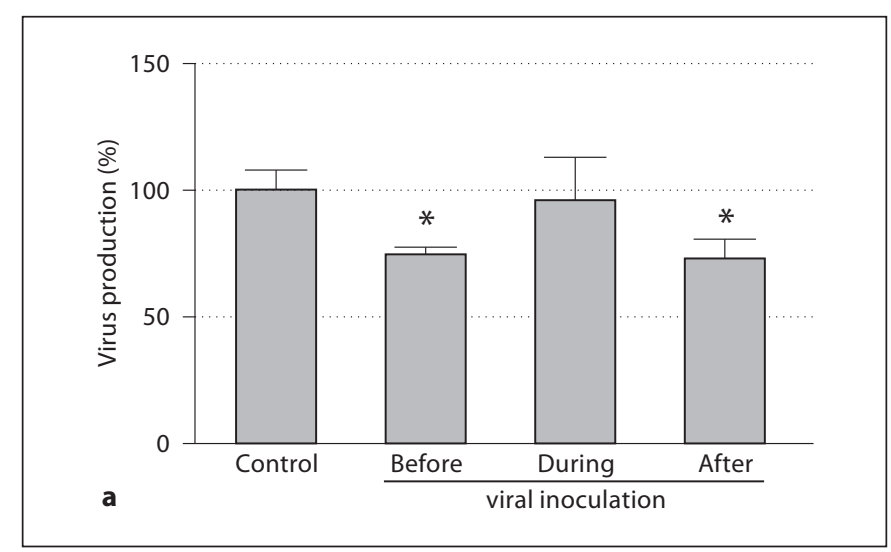

Fig. 4. Virus yield in VERO (a) and HMEC-1 (b) cells treated with LOV. Cells were treated with $20 \mu \mathrm{M} \mathrm{LOV}$ before, during or afterviral inoculation (MOI 1). Twenty-four hours later, supernatants were removed and titrated by plaque assay to measure the amount of infectious viral particles released from cells. The values repre-

began at approximately $6 \mathrm{~h}$ after infection and increased consistently until $20 \mathrm{~h}$ (fig 5a). In HMEC-1 cells, viral uncoating, protein synthesis, and genome replication and transcription occurred within the first $6 \mathrm{~h}$ after inoculation, with assembly and maturation beginning at $6 \mathrm{~h}$ and continuing until $10 \mathrm{~h}$. DENV release from HMEC-1 cells began at $8 \mathrm{~h}$ after infection and remained constant until $20 \mathrm{~h}$ (fig. 5b). A peak in viral budding or exocytosis occurred at $20 \mathrm{~h}$ after inoculation. In a time course assay of LOV inhibition, we found that LOV inhibits infection when added within the first $12 \mathrm{~h}$ after inoculation for

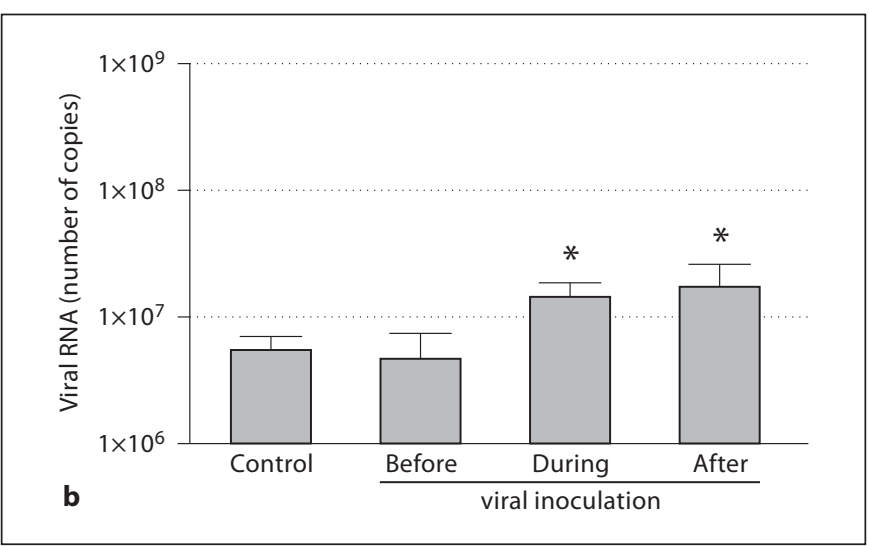

represent the means \pm SEM of 2 independent experiments with 2 replicates for each condition $(n=4)$. The asterisk indicates a significant difference compared with LOV-untreated controls (Student's t test; $\mathrm{p}<0.05$ ).

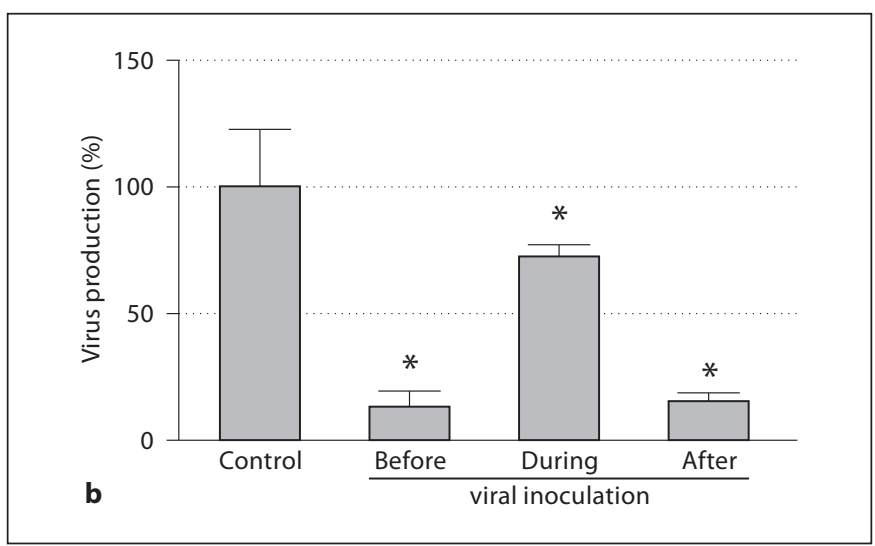

sent the means \pm SEM of 2 independent experiments with 3 replicates for each condition $(n=6)$. The asterisk indicates a significant difference compared with LOV-untreated controls (Student's t test; $\mathrm{p}<0.05)$.

VERO cells (fig. 5c), and within the first $6 \mathrm{~h}$ after inoculation for HMEC-1 cells (fig. 5d).

\section{Isoprenoids Do Not Reverse the Inhibition Induced by $L O V$}

To identify the mechanism by which LOV inhibits infectious DENV particle production, we treated VERO and HMEC-1 cells with LOV, alone or in the presence of MEV pathway agonists and antagonists, before or after viral inoculation. MEV rescued the LOV-induced inhibition of infectious DENV particles in VERO cells when 

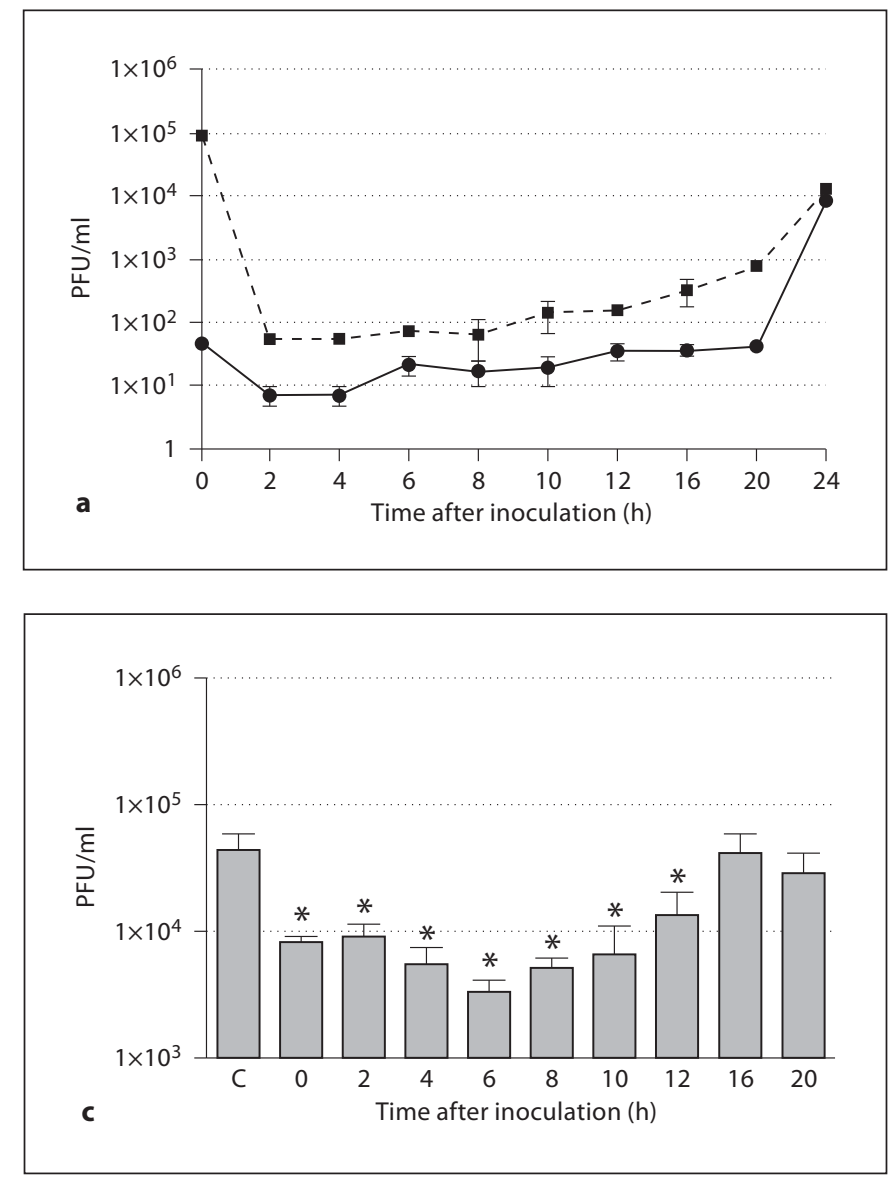

Fig. 5. Time course of LOV inhibition of infectious viral particle production. One-step virus growth in HMEC-1 (a) and VERO (b) cells. The cells were infected with DENV at a MOI of 10 and the monolayers and supernatants were titrated by plaque assay at different times $(0,2,4,6,8,10,12,16,20$ and $24 \mathrm{~h})$ after infection in order to quantify the cell-associated virus (----) and extracellular (-) virions. Independent cultures of HMEC-1 (c) and VERO (d) cells were infected with DENV-2 at a MOI of 10 and LOV

LOV was added before (fig. 6a) or after (fig. 6b) virus inoculation. Nevertheless, cholesterol or the isoprenoids GGPP or FPP did not reverse LOV-induced inhibition in these conditions. LOV-induced inhibition of infectious DENV was not rescued by coaddition of MEV in HMEC1 cells (fig. 6c, d). Incubation of VERO and HMEC-1 cells with the specific inhibitors of geranyl transferase I (GGTI268) and farnesyl transferase (FTI-277 before (fig. 6a, c) or after (fig. 6b, d) viral inoculation did not affect infectious DENV particle production, which is consistent with the fact that the effect of LOV is not mediated by depletion of the isoprenoid pool in these cells.
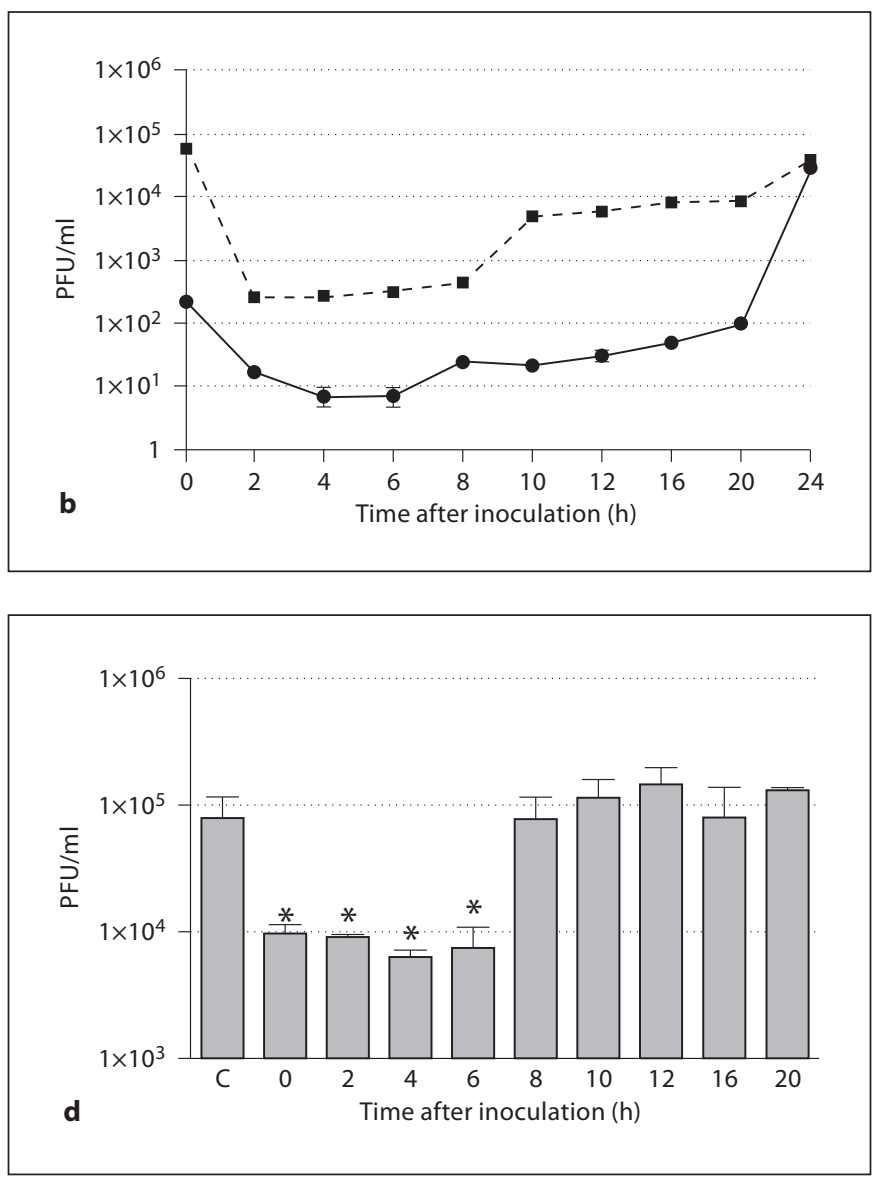

$(10 \mu \mathrm{M})$ was added once (at $0,2,4,6,8,10,12,16$ or $20 \mathrm{~h}$ ) after viral inoculation. After $24 \mathrm{~h}$, the amount of viral infectious particles in the supernatants was measured in a plaque assay. The values are the means \pm SEM of 2 independent experiments with 2 replicates for each condition $(n=4)$. The asterisk indicates a significant difference compared with the control without LOV (Student's t test; $\mathrm{p}<0.05)$.

\section{LOV Affects the Subcellular Distribution of Viral Protein in VERO and HMEC-1 Cells}

To determine the effects of LOV on the subcellular distribution of viral proteins, VERO and HMEC-1 cells were grown on coverslips and treated with LOV before (fig. 7g, i), during (fig. 7j, 1), or after (fig. $7 \mathrm{~m}, \mathrm{o}$ ) viral inoculation at MOI 10. Twenty-four hours later, the cells were processed for fluorescence microscopy assay under conditions that preserve the delicate elements of the cytoskeleton. We found a strong accumulation of viral protein around cell nuclei (fig. 7a-f). Mock-infected cells (fig. $7 \mathrm{a}-\mathrm{c}$ ) and cells mock treated with statins (fig. $7 \mathrm{~d}-\mathrm{f}$ ) 

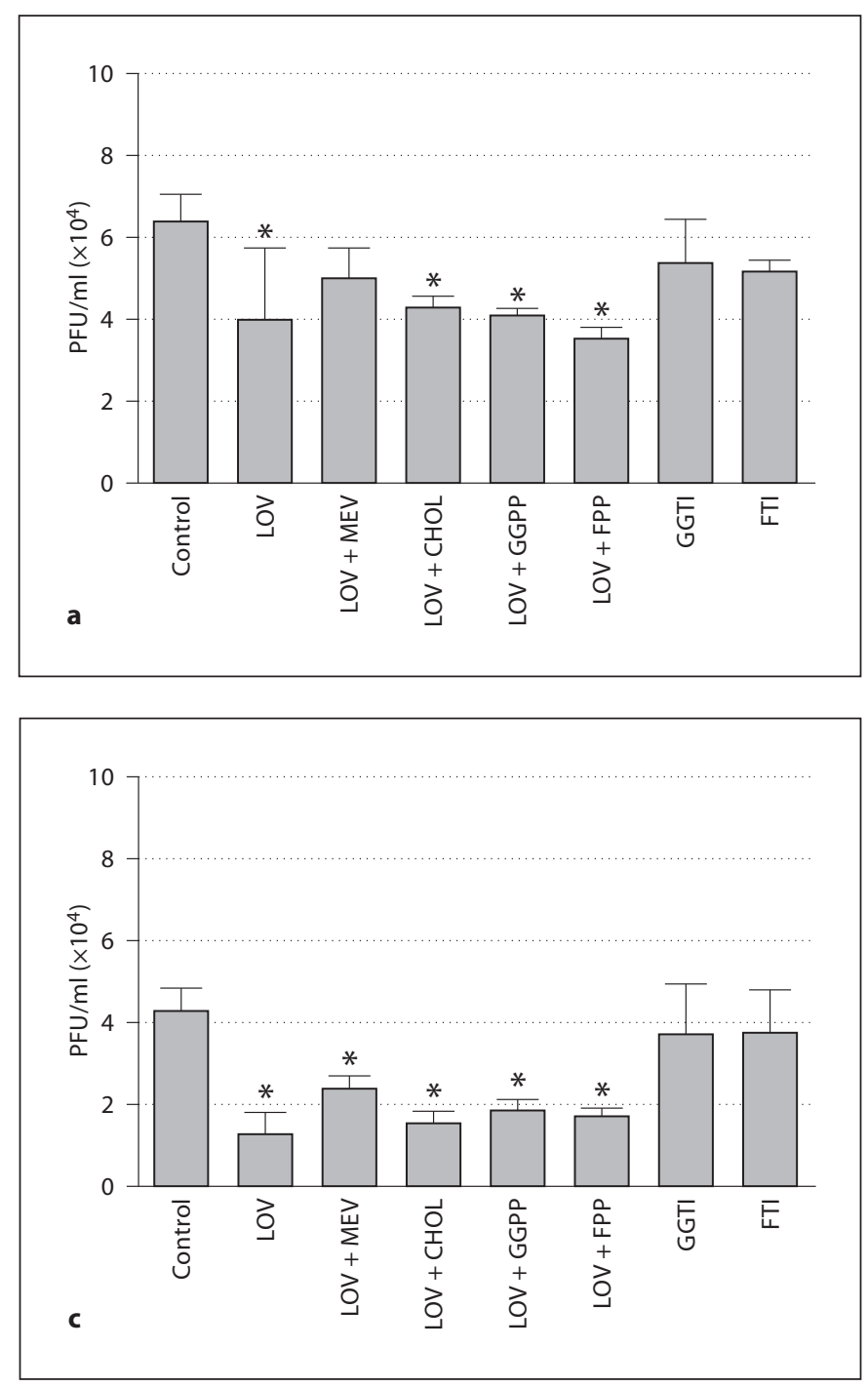

Fig. 6. Effects of agonists and antagonists of the MEV pathway on DENV-inhibition by LOV. VERO (a, b) and HMEC-1 (c, d) cells were treated with $20 \mu \mathrm{M}$ LOV alone or with $200 \mu \mathrm{M} \mathrm{MEV}, 5 \mu \mathrm{g} /$ $\mathrm{ml}$ cholesterol (CHOL), $5 \mu \mathrm{M}$ GGPP or $5 \mu \mathrm{M}$ FPP. In some cases, cultures were treated with $10 \mu \mathrm{M}$ GGTI-286 or $10 \mu \mathrm{M}$ FTI-277 alone. These treatments were performed before $(\mathbf{a}, \mathbf{c})$ or after $(\mathbf{b}$,
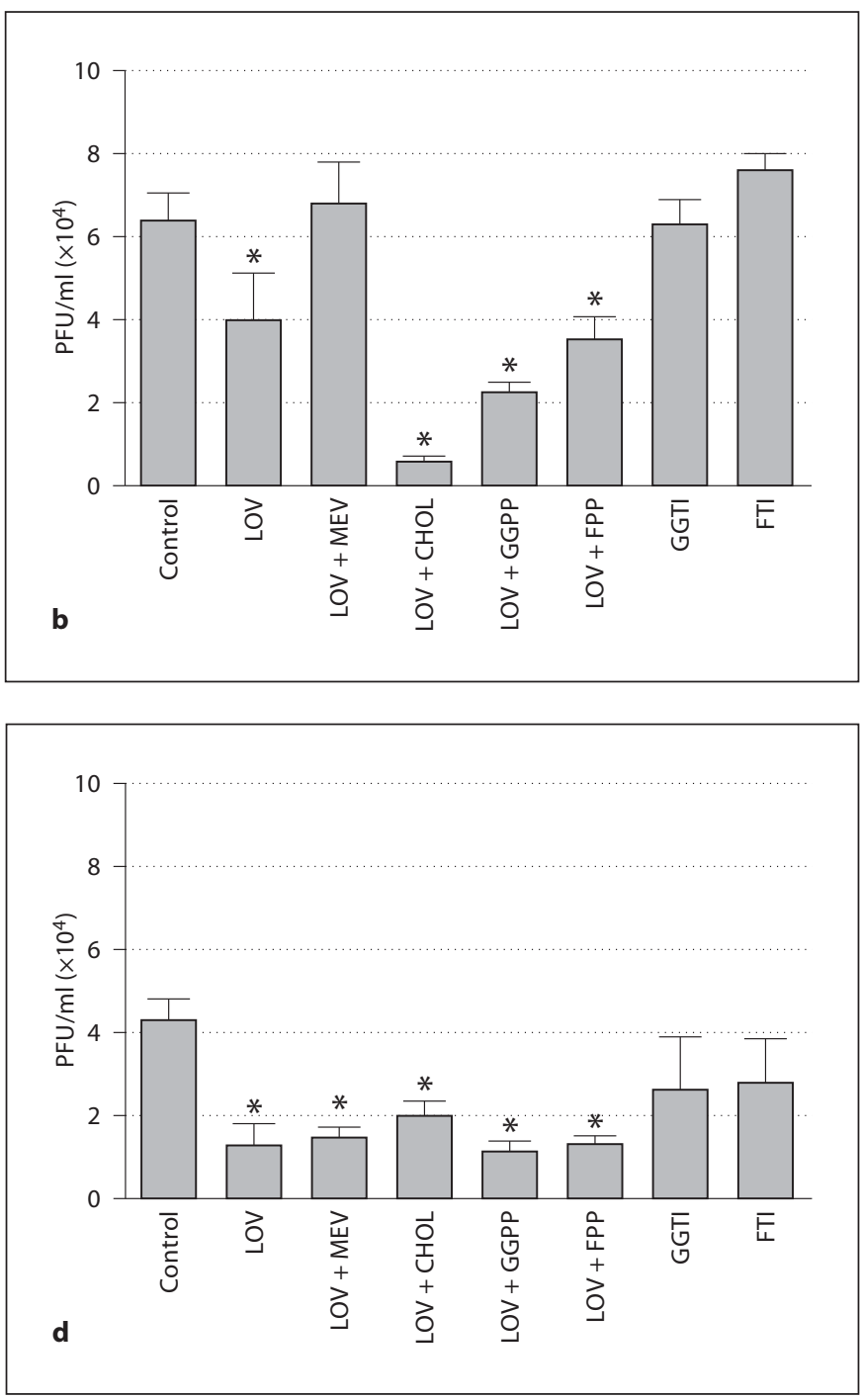

d) viral inoculation. After $24 \mathrm{~h}$, the supernatants were removed and titrated by plaque assay to measure the amount of infectious viral particles released from cells. The values represent the means \pm SEM of 2 independent experiments with 2 replicates for each condition $(n=4)$. The asterisk indicates a significant difference compared with LOV-untreated controls (Student's t test; $\mathrm{p}<0.05$ ). displayed normal cytoskeletal appearance, with patterns of stress fibers typical of those seen in epithelial cells, including VERO cells. Moreover, the nuclear labeling indicates that the cells were in interphase, with heterochromatin and euchromatin in normal patterns and no evidence of nuclear condensation or other signs of apoptosis. In both the pre- (fig. $7 \mathrm{~g}-\mathrm{i}$ ) and post-treatment (fig. $7 \mathrm{j}-\mathrm{l}$ ) schemas, statins caused notable disassembly of stress fibers with a loss of actin cables. In LOV-treated infected cells, we observed DENV E protein in a diffuse pattern with weak immunolabeling, called 'nonassembled viral protein' (fig. 7d, j) and an aggregated pattern with clear immunolabeling of DENV E protein called 'assembled viral protein', which was organized in structures similar to aggregated vesicles and larger in LOV-treated and DENV-infected cells (fig. $7 \mathrm{~m}$ ) compared with untreated cells (fig. 7d). 

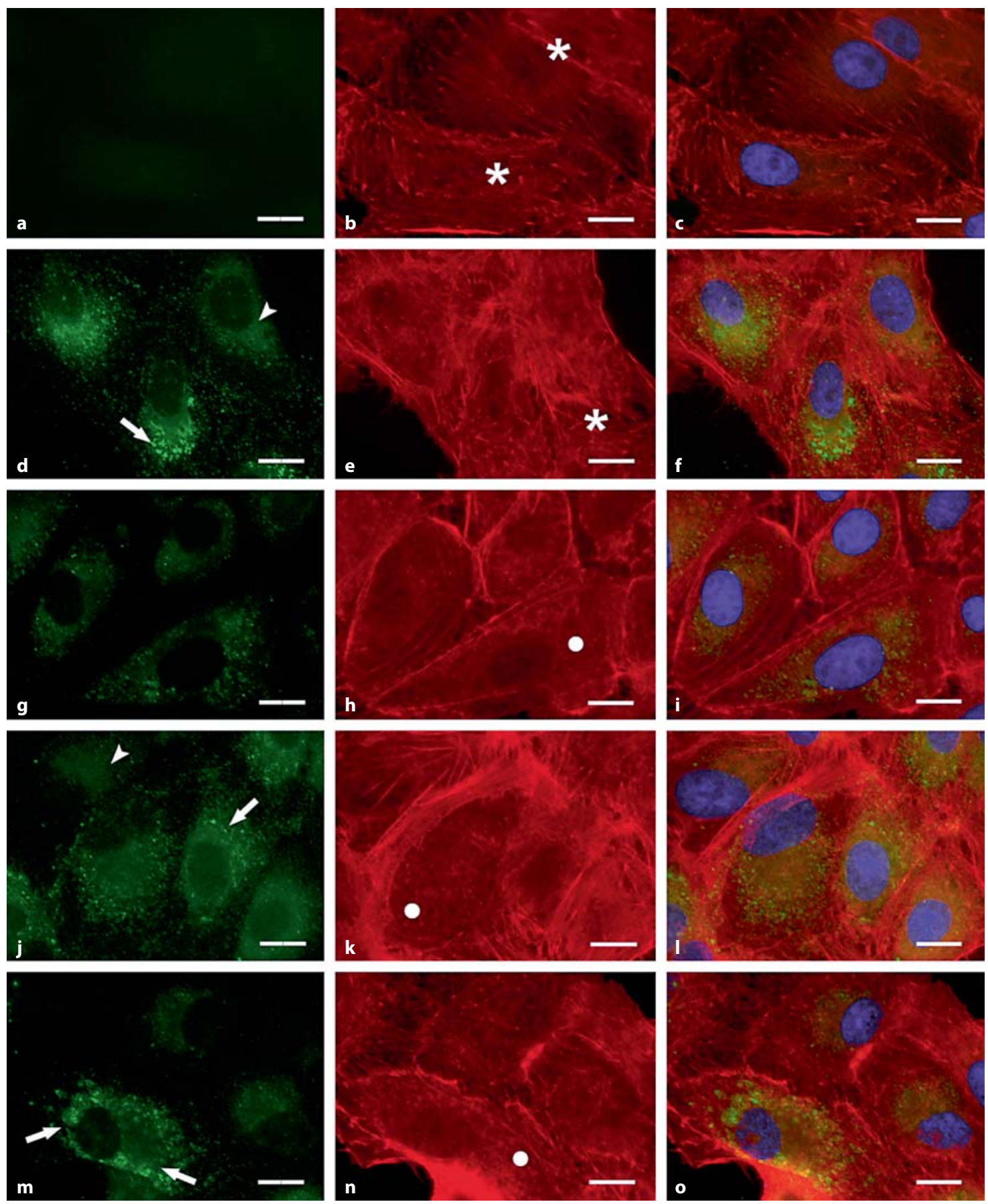

Fig. 7. Subcellular distribution of viral proteins in VERO cells. Some cultures were not treated with LOV and not infected with DENV-2 (a-c); others were not treated with LOV but were infected with DENV-2 (d-f), and others were subjected to various experimental strategies: before viral inoculation $(\mathbf{g}-\mathbf{i})$, during viral inoculation (j-I) and after viral inoculation $(\mathbf{m}-\mathbf{0})$. At $48 \mathrm{~h}$ after inoculation, cell monolayers were fixed and processed for microscopy while preserving the delicate elements of the cytoskeleton. Viral proteins were detected with an antibody against E protein and a secondary antibody conjugated with Alexa 488 (a, d, g, j, m); cellular actin was conjugated with phalloidin $(\mathbf{b}, \mathbf{e}, \mathbf{h}, \mathbf{k}, \mathbf{n})$. Merge is shown in $\mathbf{c}, \mathbf{f}, \mathbf{i}, \mathbf{I}$ and $\mathbf{o}$. Images were obtained using an inverted microscope (IX-81 Olympus ${ }^{\circledR}$ ) and processed by software (Media Cybernetics, Image Pro Plus $\left.{ }^{\circledR}\right)$. Asterisks indicate cells with normal stress fibers and dots indicate cells in which stress fibers have been lost almost entirely. LOV induced great accumulation of viral protein in DENV-infected cells in two patterns: viral protein in a diffuse pattern called 'nonassembled viral protein' (arrowheads), and viral protein in structures similar to aggregated vesicles called 'assembled viral protein' arrow). Scale bar: $10 \mu \mathrm{m}$. 


\section{Discussion}

There is growing evidence for the role of statins in controlling various viral infections, including DENV. In this work, we used epithelial and endothelial cellular models of infection with DENV in combination with different strategies for treatment with statins. We measured infectious viral particles, intracellular viral protein, and RNA from viral genomes. We presented a cellular mechanism which could explain the antiviral effect of LOV via the combination of cholesterol metabolism and inhibition of isoprenylation of Rho GTPases and vesicle trafficking. We demonstrated that the subcellular patterns of viral proteins we observed are in accordance with an impaired viral assembly process that normally occurs in the ER and membranes derived of the endocytic/exocytic pathway.

In this research, the antiviral effect of LOV, the principal statin used in humans, on DENV-2 infection in VERO cells was evaluated in two in vitro models, VERO and HMEC-1 cells, both of which have been reported to be highly permissive for infection by DENV and have been frequently used in in vitro studies of DENV infection $[41,42]$. The effects of LOV on the production of viral protein, viral RNA and infectious viral particles were evaluated using three experimental treatment approaches: before, during and after viral inoculation. The statins were selected because they are conventionally used in the treatment of hypercholesterolemia, and are very safe and well tolerated even at high doses [43]. Moreover, it has been demonstrated that statins can inhibit the replication of several viruses [25-29] and the associated subsequent disease progression $[27,30]$.

One of the main approaches to the problem of dengue disease control could be drug therapy; however, there are currently no anti-DENV drugs available. Several compounds from different sources have shown antiviral activity against DENV in in vitro models [7], but until now none of these have been used in humans and just one has been tested in an animal model, demonstrating significant reduction in viremia $[44,45]$ and increased survival time [46]. The World Health Organization recommended that dengue research be focused on specific areas, including the evaluation of new products and existing licensed drugs with good safety profiles [47].

In LOV-pretreated cells, we observed a reduction in viral protein synthesis and a reduction in the proportion of infected cells compared with nontreated cultures. In addition, the number of infectious viral particles released was significantly lower than in untreated cells. It has been reported that treatment of human monocytes/macrophages [11] or neuroblastoma cells [45] with a lipid raft disrupter that depletes cellular cholesterol (methyl- $\beta-c y-$ clodextrin) before infection with DENV decreases the number of virus particles released from cells, further suggesting that cholesterol is important during DENV entry. Taking into account that LOV decreases cholesterol synthesis, the reduction in the number of infected cells and viral particles could be due to cholesterol reduction causing a decrease in viral entry into the cells. Moreover, it has recently been reported that Rab5 protein is involved in DENV endocytosis [48]. The isoprenylation of this protein should to be inhibited by LOV, thereby affecting viral endocytosis. However, it is interesting that we did not find a reduction in the amount of viral RNA; instead, we observed a slight accumulation of viral protein inside infected cells in pretreated cultures. This could indicate that, in spite of viral entry being affected in some (approx. 50\%) cells, the process of protein synthesis and RNA replication in cells that become infected occurs normally.

When LOV was added during viral inoculation, we did not find any changes in the number of infected cells or in the amount of viral protein in either type of cells (VERO and HMEC-1). This result could indicate that LOV does not interfere with the normal cellular processing of the DENV receptor present in the cell membrane or that LOV has no virucidal effect. However, we found a strong accumulation of viral RNA inside the HMEC-1 cells as well as a slight reduction in the number of infectious viral particles released. Our results demonstrate that in HMEC-1 cells $1 \mathrm{~h}$ of treatment with LOV is sufficient for uptake and effectiveness of the compound, enabling it to inhibit cellular processes that subsequently affect the assembly or release of new virus. Since these changes were observed only in endothelial (HMEC-1) cells, we think that endothelial cells are probably more sensitive to the antiviral effects of LOV than are fibroblasts.

These data are consistent with the fact that HMEC-1 cells have a high capacity for vesicle transport mediated by caveolae and clathrin [49]. It is known that both types of transport are essential in inward and outward cellular cholesterol traffic [50]. Additionally, HMEC-1 cells have been used as a model for the exocytic/endocytic pathway involving Rab GTPases [51]. These reports, together with our findings, suggest that endothelial cells are especially susceptible to alterations in cholesterol transport induced by statins. The increased inhibition of HMEC-1 cells, compared with epithelial cells, may be due to the more 
dynamic vesicle trafficking and, by extension, the constant functioning of lipids in the endothelial cells. Although endothelial cells have not been shown to be direct targets of DENV [52], progress toward discovering the role of the endothelial microvasculature in DENV pathogenesis may aid in the development of drugs with stronger antiviral effects against DENV.

We found that viral protein and viral RNA increased in cultures treated with LOV after viral inoculation. Moreover, we did not observe a reduction in the proportion of infected cells but a strong accumulation of viral protein inside the cells. In concordance with these results, we found a reduction in infectious viral particles released in the supernatant. Mohan et al. [28] recently found an increase in intracellular viral protein in MA104 cells infected with rotavirus and subsequently treated with LOV. Moreover, they observed an increase in the number of 'empty-looking' particles seen by electron microscopy in supernatants from these cells, which suggests a defect in virus assembly. Considering these results, we propose that, despite the fact that replication and protein synthesis were successfully completed, the release of new viral particles from cells treated with LOV after infection is blocked. The participation of Rab8 protein in the traffic of DENV proteins from RER to Golgi has recently been reported [53]. These data suggest that the inhibition of isoprenylation of this protein could directly affect the maturation of new viral particles.

To try to identify the steps in the replication cycle of DENV that are inhibited by LOV, we studied the time course of LOV inhibition of the production of viral infectious particles. The results suggest that LOV may inhibit the final steps of the replication cycle (maturation and release) of VERO and HMEC-1 cells and are consistent with the accumulation of viral RNA and viral protein inside the cells in cultures treated with LOV after viral inoculation.

The fact that treatment with LOV inhibits the maturation and release of new virus but does not affect protein synthesis or RNA replication could be explained by an alteration in the endomembrane compartments involved in the assembly process as observed by transmission electron microscopy by Chu and Yang [54], who reported that blockade of the Src kinase pathway by antitumor drugs produces drastic inhibition of DENV infection in cell cultures. They concluded that the inhibition of c-Src protein kinases may contribute to retention of viral $\mathrm{E}$ protein within the ER, which blocks the assembling process or/ and or hampers the intracellular transport of mature virions but in the exocytic pathway.

Antiviral Effects of Statins on Dengue Virus Infection
We tried to identify the mechanism(s) by which LOV inhibited viral infection by treating the cell cultures with agonists (MEV, cholesterol, GGPP and FPP) or antagonists (GGTI-268 and FTI-277) of the MEV pathway in the presence of LOV. In VERO cells, MEV completely reversed the inhibition induced by LOV administered both before and after viral inoculation. Unexpectedly, MEV did not completely reverse the inhibition in HMEC-1 cells with any kind of treatment; this could indicate that MEV pathway-independent mechanisms are involved in this inhibition. However, little is known about this kind of mechanism. Moreover, we found that LOV inhibition of DENV infection was not reversed by cotreatment with cholesterol; in some cases, the addition of cholesterol after viral inoculation enhanced inhibition. These results are consistent with the finding that exogenous cholesterol added to cell cultures blocked the entry and replication of DENV [55]. Finally, we found that treatment with GGTI-286, which inhibits the prenylation of Rho proteins, or FTI-277, which inhibits the prenylation of Ras proteins, did not inhibit DENV infection. These results suggest that the antiviral activity of LOV cannot be completely explained by the reduction of cholesterol or inhibition of prenylation of Rho (which is usually geranylgeranylated) and Ras proteins (which are often farnesylated). However, LOV viral inhibition could be due to its inhibition of the prenylation of other proteins, such as Rab, that are involved at several steps of the DENV replicative cycle [48-53].

Recently, it has been reported that glucose-regulated protein 78 (GRP78), which resides principally within the ER, interacts with domain III of DENV E protein [56]. Knockdown of this protein reduces the production of infectious DENV particles [57], suggesting an important role of this chaperone in the correct folding of DENV proteins. Moreover, it has also been reported that statins induce the expression of GRP78 and facilitate its function [58]. Therefore, it appears that statins could favor DENV infection. However, the overexpression of GRP78 occurs in response to blockade of protein isoprenylation, principally that of Ras, Rac and Rho proteins, and our results show that these isoprenylation pathways are not involved in the inhibition of infection induced by LOV.

In spite of the theoretical issues surrounding the cholesterol biosynthetic pathway and the several pleiotropic effects of statins caused by the inhibition of prenylation of multiple cellular proteins, other researchers have found that the agonists and antagonists of these metabolic steps are partially functional and that restoration is not complete [34]. They explain that proteins that are prenylated

Intervirology 2011;54:202-216 
are not the cause of alterations in DENV infections but instead implicate sterol branching, an alternative pathway of cholesterol synthesis not conventionally considered. Recently, relevant findings have been reported regarding cholesterol and the secretory pathway. In Chinese hamster ovary cells depleted of cholesterol in the medium and treated with statins, the transport of secretory membrane proteins between the ER and the Golgi complex was blocked. Specifically, evidence that several resident proteins of the Golgi apparatus are not altered by statin treatment is presented. On the contrary, COP II, a secretory protein implied in vesicular transport or exit from the ER, was impaired [59].

It is important to remember that, in general, the assembly of viruses is not a completely efficient process since viral genomes and structural proteins are often recruited to a viral factory or assembly site in which several additional cellular components are required (i.e. molecules and structures derived from some organelle). The coordination in time and in space of these events is necessarily very complex. It is therefore often observed that viral proteins and viral genomes occur in excess, in which case they are commonly known as 'by-products' [60]. Recently, other research groups have found that the $\mathrm{PFU} /$ particle ratios for DENV are extremely low, ranging from $1 / 2,600$ to $1 / 7,200$. This indicates that, for this virus, the assembly process is inefficient and that most of the viral particles produced in cellular infection are without infectivity, with only a minor percentage representing infectious virions [61]. It is therefore not surprising that we can find evidence of viral infections in which a large amount of viral proteins and viral genomes present are not actually assembled, and in which even a high proportion of the assembled particles are not infective. Therefore, a block in the assembly process can produce a drastic increase in DENV virus RNA and protein with only a moderate reduction in virions. Based on the facts of viral biology regarding PFU/particle ratios, the assembly process and viral factories, and considering our data obtained using a highly preservative fixation technique for the cytoskeleton, our observations are perfectly compatible with the existence of both 'nonassembled viral protein' and 'assembled viral protein,' as described above, in DENV-infected cells.

This panorama in the context of a natural infection could lead to an unknown response during in vivo treatment with LOV. Unpublished results obtained by our group have shown that LOV retards disease progression in infected mice (AG129), but in fact it does not reduce viremia [62]. Further experiments with this animal mod- el will help clarify the actual benefits of statin therapy in dengue disease.

Taken together, our results indicate that several cellular mechanisms are affected by LOV, resulting in a moderate inhibition of productive infection in VERO and HMEC-1 cells. If LOV is added to the cultures before viral inoculation, virus entry is affected principally by a reduction in membrane cholesterol, but the inhibition of prenylation of Rab5 and Rab8 proteins may also contribute. When LOV is added after viral inoculation, the mechanism involved may be the inhibition of prenylation of Rab8. In both experimental strategies, LOV would inhibit DENV infection principally by affecting the transport from ER to the Golgi apparatus and in this way prevent the budding of new viral progeny.

Our data lead to the conclusion that the supposed antiviral effect of statins should be addressed with caution, but fortunately, they also show that statins are a useful novel agent that should be part of the toolkit for the study of the cellular biology of viral infections.

\section{Acknowledgments}

The authors would like to thank the Microbiology and Parasitology Department of Medicine Faculty of Universidad de Antioquia for support, Marta Ospina (Sectional Direction of Health, Department of Antioquia) for initial advice, and training and Eva Harris, Robert Beatty and Ma. Elena Peñaranda of the Sustainable Sciences Institute and University of California at Berkeley, for permanent donations, advice and training in the DENV field. Finally, the authors would like to thank Andrea Trujillo-Correa, for her excellent skills with confocal microscopy. This work was supported by Colciencias (Departamento Administrativo de Ciencia, Tecnología e Innovación) grants No. 1115-04-18079, 111540820511 and 111545921525. M.M.G received a PhD Fellowship from Colciencias.

\section{References}

1 Gubler D, Kuno G, Markoff L: Flaviviruses; in Knipe DM, Howley PM (eds): Fields Virology, ed 5. Philadelphia, Lippincott William \& Wilkins, vol 1, pp 1153-1253.

$\checkmark 2$ Black WC 4th, Bennett KE, GorrochóteguiEscalante N, Barillas-Mury CV, FernándezSalas I, de Lourdes Muñoz M, Farfán-Alé JA, Olson KE, Beaty BJ: Flavivirus susceptibility in Aedes aegypti. Arch Med Res 2002;33:379388.

3 Kyle JL, Harris E: Global spread and persistence of dengue. Annu Rev Microbiol 2008; 62:71-92.

4 PAHO: Update: Dengue Situation in the Americas. [http://new.paho.org/hq/index. php?option=com_content\&task=view\&id= 841\&Itemid=1167]. 2009 
5 Vasilakis N, Weaver SC: The history and evolution of human dengue emergence. Adv Virus Res 2008;72:1-76.

-6 Usme-Ciro JA, Mendez JA, Tenorio A, Rey GJ, Domingo C, Gallego-Gomez JC: Simultaneous circulation of genotypes I and III of dengue virus 3 in Colombia. Virol J 2008;5: $1-10$.

7 Sampath A, Padmanabhan R: Molecular targets for flavivirus drug discovery. Antiviral Res 2009;81:6-15.

8 Lindenbach BT, Thiel HJ, Rice CM: Flaviviridae: The viruses and their replication; in Knipe DM, Howley PM (eds): Fields Virology, ed 5. Philadelphia, Lippincott, William \& Wilkins, vol 1, pp 1101-1152.

9 Chen Y, Maguire T, Marks RM: Demonstration of binding of dengue virus envelope protein to target cells. J Virol 1996;70:87658772.

10 Tassaneetrithep B, Burgess TH, GranelliPiperno A, Trumpfheller C, Finke J, Sun W, Eller MA, Pattanapanyasat K, Sarasombath S, Birx DL, Steinman RM, Schlesinger S, Marovich MA: DC-SIGN (CD209) mediates dengue virus infection of human dendritic cells. J Exp Med 2003;197:823-829.

- 11 Reyes-Del Valle J, Chávez-Salinas S, Medina F, Del Angel RM: Heat shock protein 90 and heat shock protein 70 are components of dengue virus receptor complex in human cells. J Virol 2005;79:4557-4567.

12 Jindadamrongwech S, Thepparit C, Smith DR: Identification of GRP 78 (BiP) as a liver cell expressed receptor element for dengue virus serotype 2. Arch Virol 2004;149:915927.

-13 Acosta EG, Castilla V, Damonte EB: Functional entry of dengue virus into Aedes albopictus mosquito cells is dependent on clathrin-mediated endocytosis. J Gen Virol 2008;89:474-484.

14 Barth OM: Ultrastructural aspects of the dengue virus (Flavivirus) particle morphogenesis. J Submicrosc Cytol Pathol 1999;31: 407-412.

15 Cahour A, Falgout B, Lai CJ: Cleavage of the dengue virus polyprotein at the NS3/NS4A and NS4B/NS5 junctions is mediated by viral protease NS2B-NS3, whereas NS4A/ NS4B may be processed by a cellular protease. J Virol 1992;66:1535-1542.

16 Panyasrivanit M, Khakpoor A, Wikan N, Smithq DR: Co-localization of constituents of the dengue virus translation and replication machinery with amphisomes. J Gen Virol 2009;90:448-456.

17 Murray JM, Aaskov JG, Wright PJ: Processing of the dengue virus type 2 proteins prM and C-prM. J Gen Virol 1993;74:175-182.

- 18 Zybert IA, van der Ende-Metselaar $\mathrm{H}$, Wilschut J, Smit JM: Functional importance of dengue virus maturation: infectious properties of immature virions. J. Gen Virol 2008; 89:3047-3051.
19 Endo A, Kuroda M, Tanzawa K: Competitive inhibition of 3-hydroxy-3-methylglutaryl coenzyme A reductase by ML-236A and ML236B fungal metabolites, having hypocholesterolemic activity. FEBS Lett 1976;72:323326.

20 Gaw A, Packard CJ: Comparative chemistry, pharmacology and mechanism of action of the statins; in Gaw A, Packard CJ, Shepherd J (eds): Statins: The HMG-CoA Reductase Inhibitors in Perspective. London, Dunitz, 2003, pp 61-77.

21 Jasińska M, Owczarek J, Orszulak-Michalak D: Statins: a new insight into their mechanisms of action and consequent pleiotropic effects. Pharmacol Rep 2007;59:483-499.

22 Carlberg M, Dricu A, Blegen H, Wang M, Hjertman M, Zickert P, Höög A, Larsson O: Mevalonic acid is limiting for N-linked glycosylation and translocation of the insulinlike growth factor-1 receptor to the cell surface. Evidence for a new link between 3-hydroxy-3-methylglutaryl-coenzyme A reductase and cell growth. J Biol Chem 1996; 271:17453-17462.

23 McTaggart SJ: Isoprenylated proteins. Cell Mol Life Sci 2006;63:255-267.

24 Lundquist EA: Small GTPases. WormBook 2006;17:1-18.

25 Gower TL, Graham BS: Antiviral activity of lovastatin against respiratory syncytial virus in vivo and in vitro. Antimicrob Agents Chemother 2001;45:1231-1237.

26 Ye J, Wang C, Sumpter RJr, Brown MS, Goldstein JL, Gale M Jr: Disruption of hepatitis C virus RNA replication through inhibition of host protein geranylgeranylation. Proc Natl Acad Sci USA 2003;100:15865-15870.

27 del Real G, Jiménez-Baranda S, Mira E, Lacalle RA, Lucas P, Gómez-Moutón C, Alegret M, Peña JM, Rodríguez-Zapata M, AlvarezMon M, Martínez C, Mañes S: Statins inhibit HIV-1 infection by down-regulating Rho activity. J Exp Med 2004;200:541-547.

28 Mohan KV, Muller J, Atreya CD: Defective rotavirus particle assembly in lovastatintreated MA104 cells. Arch Virol 2008;153: 2283-2290.

29 Potena L, Frascaroli G, Grigioni F, Lazzarotto T, Magnani G, Tomasi L, Coccolo F, Gabrielli L, Magelli C, Landini MP, Branzi A: Hydroxymethyl-glutaryl coenzyme A reductase inhibition limits cytomegalovirus infection in human endothelial cells. Circulation 2004;109, 532-536.

30 Bader T, Fazili J, Mdhoun M, Aston C, Hughes D, Rizvi S, Seres K, Hasan M: Fluvastatin Inhibits Hepatitis C Replication in Humans. Am J Gastroenterol 2008; 103: 1383-1389.

1 Noisakran S, Dechtawewat T, Avirutnan P, Kinoshita T, Siripanyaphinyo U, Puttikhunt C, Kasinrerk W, Malasit P, Sittisombut N: Association of dengue virus NS1 protein with lipid rafts. J Gen Virol 2008;89:24922500 .
32 Medigeshi GR, Hirsch AJ, Streblow DN, Nikolich-Zugich J, Nelson JA: West Nile virus entry requires cholesterol-rich membrane microdomains and is independent of

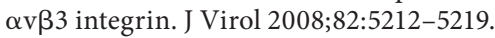

33 Das S, Chakraborty S, Basu A: Critical role of lipid rafts in virus entry and activation of phosphoinositide 3' kinase/Akt signaling during early stages of Japanese encephalitis virus infection in neural stem/progenitor cells. J Neurochem DOI: 10.1111/j.1471-4159. 2010.06951.

-34 Rothwell C, Lebreton A, Young Ng C, Lim JY, Liu W, Vasudevan S, Labow M, Gu F, Gaither LA: Cholesterol biosynthesis modulation regulates dengue viral replication. Virology 2009;389:8-19.

-35 Talarico LB, Pujol CA, Zibetti RG, Faría PC Noseda MD, Duarte ME, Damonte EB: The antiviral activity of sulfated polysaccharides against dengue virus is dependent on virus serotype and host cell. Antiviral Res 2005;66: 103-110.

36 Rincón V, Corredor A, Martínez-Gutiérrez M, Castellanos JE: Fluorometric cell-ELISA for quantifying rabies infection and heparin inhibition. J Virol Methods 2005;127:33-39.

37 Houghton-Triviño N, Salgado DM, Rodríguez JA, Bosch I, Castellanos JE: Levels of soluble ST2 in serum associated with severity of dengue due to tumour necrosis factor $\alpha$ stimulation. J Gen Virol 2010;91:697-706.

- 38 Gallego-Gómez JC, Risco C, Rodríguez D, Cabezas P, Guerra S, Carrascosa JL, Esteban M: Differences in virus-induced cell morphology and in virus maturation between MVA and other strains (WR, Ankara, and $\mathrm{NYCBH}$ ) of vaccinia virus in infected human cells. J Virol 2003;77:10606-10622.

39 Rossner M, O’Donnell R: The JCB will let your data shine in RGB. J Cell Biol 2004;164: 11-13.

40 Rossner M, Yamada KM: What's in a picture? The temptation of image manipulation. J Cell Biol 2004;166:11-15.

41 Martínez-Barragán JJ, del Angel RM: Identification of a putative coreceptor on VERO cells that participates in dengue 4 virus infection. J Virol 2001;75:7818-7827.

- 42 Talavera D, Castillo AM, Dominguez MC Gutierrez AE. Meza I: IL8 release, tight junction and cytoskeleton dynamic reorganization conducive to permeability increase are induced by dengue virus infection of microvascular endothelial monolayers. J Gen Virol 2004;85:1801-1813.

-43 Escobar C, Echarri R, Barrios V: Relative safety profiles of high dose statin regimens. Vasc Health Risk Manag 2008;4:525-533.

-44 Schul W, Liu W, Xu HY, Flamand M, Vasudevan SG: A dengue fever viremia model in mice shows reduction in viral replication and suppression of the inflammatory response after treatment with antiviral drugs. J Infect Dis 2007;195:665-674. 
45 Lee E, Pavy M, Young N, Freeman C, Lobigs M: Antiviral effect of the heparan sulfate mimetic, PI-88, against dengue and encephalitic flaviviruses. Antiviral Res 2006;69:3138.

46 Stein DA, Huang CY, Silengo S, Amantana A, Crumley S, Blouch RE, Iversen PL, Kinney RM: Treatment of AG129 mice with antisense morpholino oligomers increases survival time following challenge with dengue 2 virus. J Antimicrob Chemother 2008;62: 555-565.

-47 Farrar J, Focks D, Gubler D, Barrera R, Guzman MG, Simmons C, Kalayanarooj S, Lum L, McCall PJ, Lloyd L, Horstick O, DayalDrager R, Nathan, MB, Kroeger A, WHO/ TDR Dengue Scientific Working Group: Towards a global dengue research agenda. Trop Med Int Health 2007;12:695-699.

-48 Krishnan MN, Sukumaran B, Pal U, Agaisse $\mathrm{H}$, Murray JL, Hodge TW, Fikrig E: Rab 5 is required for the cellular entry of dengue and West Nile viruses. J Virol 2007;81:48814885 .

49 Ring A, Pohl J, Völkl A, Stremmel W: Evidence for vesicles that mediate long-chain fatty acid uptake by human microvascular endothelial cells. J Lipid Res. 2002;43:20952104.

50 Schnitzer JE, Oh P, Pinney E, Allard J: Filipin-sensitive caveolae-mediated transport in endothelium: reduced transcytosis, scavenger endocytosis, and capillary permeability of select macromolecules. J Cell Biol 1994; 127:1217-1232.
51 Ward ES, Martinez C, Vaccaro C, Zhou J, Tang Q, Ober RJ: From sorting endosomes to exocytosis: association of Rab4 and Rab11 GTPases with the Fc receptor, FcRn, during recycling. Mol Biol Cell 2005;16: 2028-2038.

52 Basu A, Chaturvedi UC: Vascular endothelium: the battlefield of dengue viruses. FEMS Immunol Med Microbiol 2008; 53: 287-299.

$53 \mathrm{Xu}$ XF, Chen ZT, Zhang JL, Chen W, Wang JL, Tian YP, Gao N, An J: Rab8, a vesicular traffic regulator, is involved in dengue virus infection in HepG2 cells. Intervirology 2008; 51:182-188.

54 Chu JJ, Yang PL: c-Src protein kinase inhibitors block assembly and maturation of dengue virus. Proc Natl Acad Sci USA 2007;104: 3520-3525.

55 Lee CJ, Lin HR, Liao CL, Lin YL: Cholesterol effectively blocks entry of flavivirus. J Virol 2008;82:6470-6480.

56 Upanan S, Kuadkitkan A, Smith DR: Identification of dengue virus binding proteins using affinity chromatography. J Virol Methods 2008; 15:325-328.

57 Limjindaporn T, Wongwiwat W, Noisakran S, Srisawat C, Netsawang J, Puttikhunt C, Kasinrerk W, Avirutnan P, Thiemmeca S, Sriburi R, Sittisombut N, Malasit P, Yenchitsomanus PT: Interaction of dengue virus envelope protein with endoplasmic reticulumresident chaperones facilitates dengue virus production. Biochem Biophys Res Commun 2009;379:196-200.
8 Chen JC, Wu ML, Huang KC, Lin WW: HMG-CoA reductase inhibitors activate the unfolded protein response and induce cytoprotective GRP78 expression. Cardiovasc Res 2008;80:138-150.

59 Ridsdale A, Denis M, Gougeon PY, Ngsee JK, Presley JF, Zha X: Cholesterol is required for efficient endoplasmic reticulum-to-Golgi transport of secretory membrane proteins. Mol Biol Cell 2006;17:1593-1605.

60 Novoa RR, Calderita G, Arranz R, Fontana J Granzow H, Risco C: Virus factories: associations of cell organelles for viral replication and morphogenesis. Biol Cell 2005;97:147172.

61 van der Schaar HM, Rust MJ, Waarts BL, van der Ende-Metselaar H, Kuhn RJ, Wilschut J, Zhuang X, Smit JM: Characterization of the early events in dengue virus cell entry by biochemical assays and single-virus tracking. J Virol 2007;8:12019-12028.

62 Martinez-Gutierrez M, Castellanos JE, Correa L, Gallego-Gomez JC, Osorio J: Lovastatin retards diseases progression and enhances survival in AG129 mice infected with dengue virus 2(unpublished results, 2010). 